\title{
Accountability e regulação da educação básica municipal no estado do Ceará - Brasil
}

\author{
Anderson Gonçalves Costa (D) @ \\ Eloisa Maia Vidal \\ Universidade Estadual do Ceará (UECE), Brasil
}

Resumo. As políticas de accountability educacional têm sido globalizadas nos últimos anos na esteira das transformações da ação estatal. Entretanto, as lógicas subjacentes a elas têm variado de acordo com os contextos políticos, históricos e sociais de cada local. Neste artigo, aborda-se o sistema de accountability instituído no estado do Ceará (Brasil) ao nível das redes e escolas municipais. De natureza qualitativa, foi utilizada, como procedimento metodológico, a análise de documentos oficiais e técnicos produzidos pelo governo estadual do Ceará. Do ponto de vista conceitual, utilizou-se da teoria da regulação das políticas educacionais. A tessitura de constituição do sistema de accountability no Ceará revela um processo de coordenação federativa à luz da regulação institucional, própria do movimento de internacionalização das políticas educacionais e beneficiado por aspectos históricos e políticos dessa unidade subnacional.

Palavras-chave: accountability; regulação; educação municipal; Ceará; Brasil.

Accountability y regulación de la educación básica municipal en el estado de Ceará - Brasil Resumen. Las políticas de accountability en educación se han globalizado en los últimos años siguiendo la senda de las transformaciones estatales. Sin embargo, sus discursos subyacentes varían según los contextos políticos, históricos y sociales de cada zona. En este artículo, se enfoca el sistema de accountability instituido en el estado de Ceará (Brasil) a nivel de las redes y escuelas municipales. De carácter cualitativo, se ha utilizado como procedimiento metodológico el análisis de documentos oficiales y técnicos producidos por el gobierno de Ceará. Desde el punto de vista conceptual, se ha aplicado la teoría de la regulación de las políticas educativas. La estructura que constituye el sistema de accountability en Ceará demuestra un proceso de coordinación federativa en conformidad con la regulación institucional, propia del movimiento de internacionalización de las políticas educativas y que se beneficia de los aspectos históricos y políticos de esta unidad subnacional.

Palabras clave: accountability; regulación; educación municipal; Ceará; Brasil.

Accountability and regulation of municipal basic education in the state of Ceará - Brazil

Abstract. The educational accountability policies have been globalized in recent years in the track of transformations in state action. However, the underlying logic to them have varied according to the political, historical and social characteristics of each place. In this article, we address the accountability system established in the State of Ceará (Brazil) at the level of networks and municipal schools. Of a qualitative nature, the analysis of official and technical documents produced by the state government of Ceará was used as a methodological procedure. Of a qualitative nature, it was used as a methodological procedure the analysis of official and technical documents produced by the state Government of Ceará. From a conceptual point of view, elements present in the discussion on the regulation of educational policies were used. The structure of the accountability system in Ceará reveals a process of federative coordination in the light of institutional regulation, typical of the internationalization movement of educational policies, and benefited by historical and political aspects of this subnational unit.

Keywords: accountability; regulation; municipal education; Ceará; Brazil. 


\section{Introdução}

A problemática da accountabilityno contexto educacional surge junto à elevação da educação como área importante para o desenvolvimento social, requerida por um conjunto de reformas, políticas e planos. Por accountability educacional entendem-se iniciativas de responsabilização - morais ou materiais - e prestação de contas baseadas em avaliações de desempenho. Algumas definições sobre o termo tratam de elementos comuns que sustentam esse modelo de política, como a fixação de objetivos, os instrumentos de avaliação, a divulgação de informações e as consequências que se expressam pela presença de atos de premiação ou de sanção.

No Brasil, República Federativa com 27 estados e 5.570 municípios, a implementação de políticas de accountabilitysurge em experiências pontuais, no início dos anos 2000, em algumas redes municipais e estaduais de ensino. Entretanto, a partir do ano de 2007, essas experiências se alastraram de forma mais sistematizada, influenciadas pelo redimensionamento do modelo de avaliação de larga escala nacional e a criação do Índice de Desenvolvimento da Educação Básica (IDEB). Atualmente, como informa Schneider (2017), são 26 os estados brasileiros que mobilizam ferramentas de accountability, a maioria deles operando com políticas de impactos financeiros associados a sistemas de avaliação. Essa realidade também parece ser compartilhada por parte dos municípios, entes autônomos, que são responsáveis pela oferta de educação infantil e, na maioria dos estados, por parcela expressiva do ensino fundamental. Ainda que não se tenha sistematizado quantos deles possuem políticas de responsabilização, pesquisa de Bauer, Pimenta, Horta Neto e Souza (2015), identificou que 1.573 municípios da federação já possuíam iniciativas de avaliações próprias.

Este artigo procura investigar o sistema de accountability educacional de uma unidade subnacional do Brasil, o estado do Ceará. Localizado no nordeste brasileiro, conta com 184 municípios em seu território e tem se destacado nacionalmente pelos resultados obtidos na progressão do Ideb na série histórica 2007 - 2017, especialmente nos anos iniciais de escolaridade para crianças de 6 a 10 anos. Esse feito tem sido atribuído à forte presença do governo estadual na coordenação da política educacional sobre as municipalidades associada às políticas de accountability.

Procurou-se compreender o arranjo da política de accountability educacional no Ceará a partir das mudanças da governança do estado na coordenação estadual das políticas de educação. Para isso, observaram-se as formas e os níveis em que se dão a política, os instrumentos utilizados, os textos políticos, a questão financeira e a possibilidade de influência supranacional sobre o modelo implementado. 
A pesquisa, de natureza qualitativa, utilizou como instrumento metodológico a análise documental, uma vez que os documentos "[...] constituem também uma fonte poderosa de onde podem ser retiradas evidências que fundamentem afirmações e declarações do pesquisador" (Lüdke e André, 2014, p. 45). Considerou-se que os arranjos das políticas de accountability são regulamentados a partir de textos políticos, por isso os documentos analisados foram fontes do tipo oficial (leis e decretos) e técnicos (relatórios, acordos, textos de discussão), do período 2007-2019, coletados nos sítios oficiais do governo do Ceará.

Do ponto de vista conceitual, utilizou-se de elementos presentes na discussão sobre a regulação das políticas educacionais (Afonso, 2009; Barroso, 2005; 2006; Maroy, 2011). Uma vez que esse conceito pode ser utilizado para o estudo dos "modos como são produzidas e aplicadas as regras que orientam a acção dos actores" ou dos "modos como esses mesmos actores se apropriam delas e as transformam" (Barroso, 2006, p. 12), esta pesquisa aproximou-se da primeira realidade, ao tratar de temas específicos da gestão educacional cearense sem aprofundar os efeitos sobre a realidade dos municípios.

A reflexão é apresentada, além desta introdução, em dois tópicos distintos: 1) Regulação e accountabilityeducacional; e 2) O Ceará e o sistema de accountabilityeducacional. Por fim, apresentam-se as considerações finais.

\section{Regulação e accountability educacional}

As reformas educacionais ocorridas nas últimas décadas são tributária de razões institucionais e políticas que remontam a década de 1980 nos países desenvolvidos e que foram se propagando nos países em desenvolvimento na medida em que crises financeiras tensionaram a capacidade de resposta dos governos e os limites de sua governabilidade (Aguilar, 2010).

Essas condições puseram em pauta o debate sobre a intervenção do Estado nas políticas educacionais, tendo sido necessárias medidas políticas e administrativas que alteraram os modos de regulação do poder público. Por isso, concordando com Barroso (2005, p. 727), é possível dizer que, na busca por modernizar os sistemas educacionais, buscaram-se também novos modos de regulação que forjassem "um outro estatuto à intervenção do Estado na condução das políticas públicas". 
A regulação das políticas educacionais surge como mecanismo de orientação, de coordenação e de controle sobre a dinâmica dos sujeitos e das instituições (Maroy, 2011), e, diferentemente da concepção de regulamentação - centrada no controle dos processos -, a regulação tem uma ênfase maior na avaliação da eficiência e da eficácia das políticas a partir de medidas implementadas pela autoridade educativa (Barroso, 2005). Por isso, sua concepção atende à ideia de ajuste das ações, buscando assegurar as mudanças de um sistema. Maroy (2011, p. 21), observando a transformação das políticas de regulação no cenário europeu, observou que

[e]sse regime de regulação é, doravante, trabalhado por políticas educativas cuja orientação pode ser diversificada mas que, em diferentes graus, tendem a substituir ou a superpor, a esses antigos modos de regulação, novos arranjos institucionais, tais como a promoção da avaliação (resultados, funcionamentos, pessoais), a definição de objetivos curriculares standard, a promoção da livre escolha dos pais [...]

Essas orientações apresentam lógicas diferentes, mas recaem sobre as condutas institucionais, sendo antes uma decisão política, pois resultam de uma ação pública e estatal. Para Maroy (2011, p. 22), essa intervenção tanto é normativa (produção das normas), como é cognitiva (intenção de moldar as ações dos sujeitos no interior das instituições). No entanto, não seguem um movimento linear, mas interagem com outras normas produzidas, de tal forma que

mais do que falar de regulação seria melhor falar de "multi-regulação", já que as acções que garantem o funcionamento do sistema educativo são determinadas por um feixe de dispositivos reguladores que muitas vezes se anulam entre si, ou pelo menos, relativizam a relação causal entre princípios, objectivos, processos e resultados (Barroso, 2005, p. 734).

A interação entre as normas potencializa os efeitos da regulação no quadro de governos que recorrem a modelos de governança mais amplos que se aproximam de um Estado-avaliador. Autores como Afonso (2009) e Maroy (2011) têm atribuído à emergência do Estado-avaliador as mudanças ocorridas nas últimas décadas, pois este, longe de anular-se na definição e no controle das políticas educacionais, passa a exercer uma função mais especifica na produção de informações sobre as performances, a eficácia e a eficiência dos estabelecimentos, criando uma concorrência entre eles.

Esse contexto, somado a mudanças no plano internacional, advindas da globalização da atividade financeira, afirmou novos valores educativos no âmbito do currículo, da pedagogia e da avaliação, aproximando-os dos valores do mercado, uma vez que os sistemas educacionais foram questionados quanto a sua capacidade de formar cidadãos globais. A lógica da eficiência 
no campo educacional passou a operar sob o signo das comparações internacionais que dominam a agenda mundial da educação. Sob as condições da globalização, têm ocorrido mudanças na forma de governo fundamentadas num novo referencial político e administrativo baseado em resultados. Algumas das práticas mais comuns a esse novo cenário foram sinalizadas por Anderson (2017, pp. 604-605), dentre as quais destacam-se

- a introdução de mercados e de quase-mercados dentro e entre as organizações públicas;

- o fechamento de organizações de baixo desempenho;

- a ênfase em normas especificas e em medidas de desempenho;

- uma maior ênfase em resultados e em suas mensurações, utilizando de dados quantitativos;

- a descentralização administrativa e a autonomia limitada.

Não sendo propósito deste artigo desenvolver as especificidades de cada uma dessas práticas, pode-se afirmar, no entanto, que elas resumem a forma pragmática e exigente que tem marcado a gestão dos sistemas educacionais nas últimas décadas. Isso porque tanto revelam a orientação para os resultados, como - e em decorrência desta primeira - exigem um modelo de gestão competitivo, que entregue aprendizagens discentes satisfatórias.

Esse cenário é constituído por iniciativas diversas, mas tributário de um processo de internacionalização das políticas educacionais que busca transferir, de um local a outro, experiências que lograram êxito ou aparentam tal feito. Como resultado, a adoção desses mesmos sistemas de avaliação tem propiciado tanto a modernização no fornecimento de dados relativos ao desempenho de redes escolares e alunos, como aperfeiçoado os usos que se fazem dos resultados.

Nesse contexto, surgem dois vocábulos que têm se tornado comum nas menções as políticas educacionais: governança e accountability. Embora carreguem significados diferentes, eles se completam em suas finalidades. Enquanto o primeiro traduz as mudanças nas estruturas e nos modos de atuação do governo, o segundo é uma das ferramentas utilizadas para regular os atores e as instituições educacionais. Oriunda da língua inglesa, a accountability é traduzida para o português como o ato de prestar contas e de ser responsabilizado pelos resultados alcançados. No quadro da regulação das políticas educacionais 
[...] um sistema de avaliação externa das performances dos estabelecimentos e um sistema de encorajamentos simbólicos ou materiais, até mesmo de sanção, são implantados para favorecer a melhoria das performances e o respeito ao 'contrato' assinado entre o Estado e os estabelecimentos (ou entidades de nível superior) (Maroy, 2011, p. 32).

A associação entre a avaliação e a responsabilização pela performance, da qual trata Maroy (2011), resume os objetivos da accountability. Para Afonso (2010), as políticas de accountability articulam as dimensões da responsabilização, da avaliação e da prestação de contas da seguinte forma: a prestação de contas é a dimensão informativa e de publicização de resultados, que pode ser simultânea a diferentes níveis hierárquicos; a responsabilização refere-se ao grau de recompensas, às formas de indução e às normas de conduta, e aqui encontram-se implicados o papel e ação de professores; a avaliação é a condição para o desenvolvimento de processos de prestação de contas e de responsabilização.

O termo accountability é um conceito polissêmico por conjugar alguns significados. É também uma palavra "nômade" (que transita entre as áreas do conhecimento e entre os locais), ou viajante, como a ela se refere Schedler (2004). Esse último, também adjetivou a accountability como um "conceito radial", pois, ainda que seu uso esteja condicionado às transformações contextuais, seu significado compartilha uma essência comum de answerability (informação e justificação) e enforcement (castigo).

Anderson (2005) afirma que, no campo da educação, são encontrados três tipos de sistemas de accountability: (i) os que buscam conformidade entre as ações e as normas formais, a fim de garantir o cumprimento das leis; (ii) os que são baseados na adesão as normas profissionais e (iii) aqueles orientados pelos resultados das escolas e que responsabiliza os professores pela aprendizagem dos alunos. Este último modelo tem despontado, desde a década de 1980, em países da Europa, e tem sido apontado como modelo a ser adotado pelos países da América Latina, sobretudo pela orientação de organismos internacionais como o Banco Mundial (BM) e a Organização das Nações Unidas para a Educação, a Ciência e a Cultura (Unesco).

Dada a complexidade ligada ao termo, bem como seu uso em diversas áreas do conhecimento, ainda se verifica certa imprecisão na tradução, revelando a urgência em desfazer o emaranhado conceitual que lhe circunda. No Brasil, tem-se utilizado uma tradução simples que busca aproximar-se do sentido em inglês, algumas vezes com significado composto, somente responsabilização ou prestação de contas. Tratamos dessa tradução como 
"simples", pois, na esteira de Afonso (2018), ela acaba por reduzir o significado do termo, podendo gerar equívoco na própria análise e na discussão crítica das políticas.

Sendo a tradução uma das problemáticas ligadas à accountability, há ainda uma outra face do problema, também ligada à primeira, que seria o uso das práticas de accountability em países que apresentariam condições históricas e institucionais que não atenderiam a essas práticas.

Estudos internacionais têm demonstrado os usos cada vez mais sofisticados das ferramentas de accountability educacional, que assumem formas diversas a depender dos contextos históricos, políticos e sociais dos locais onde são implantadas. O dinamismo, associado à construção dessas políticas, tem efeito, particularmente, sobre a concepção e o modelo adotado, com padrões de controle mais severos ou brandos e formas mais ou menos articuladas entre a padronização do currículo, o uso das avaliações e o controle e a punição de escolas, gestores e professores.

O comportamento de unidades subnacionais em contexto federativo na "era da accountability" foi observado por Ruff (2019) em estudo comparativo entre os estados da Virginia e de Nebraska, nos Estados Unidos. Considerando que, naquele país, os estados passaram a implementar políticas de accountability a partir dos imperativos da lei federal No Child Left Behind (NCLB), o autor avaliou os estados antes e durante a NCLB. Suas análises concluíram que as políticas de accountability foram transformadas em razão das condições estaduais.

Procurando afirmar sua autonomia frente às orientações do governo federal, tanto o estado da Virginia como o de Nebraska projetaram iniciativas individuais de políticas de avaliação e de responsabilização. Entretanto, as condições, os processos e as consequências adotadas em cada estado resultaram em sistemas de responsabilização distintos. Enquanto, no estado da Virginia, foi implementado um modelo de política verticalizado (top-down), associado a uma cultura de centralização e de alinhamento de padrões de aprendizagem, em Nebraska o fortalecimento de uma política de responsabilização a partir do controle local conseguiu envolver gestores e professores na formulação da política.

As variações na construção das políticas de accountability também foram objeto de pesquisa de Kim e Yun (2019) quando investigaram os padrões transnacionais da responsabilização educacional buscando identificar as variações internas desse tipo de política em 38 países participantes da Teaching and Learning International Survey (TALIS). Em suas considerações, os autores destacaram a accountability como um fenômeno global, permeada 
por ambiguidades e complexidades, afirmando, como anteriormente citado, que essas políticas têm uma implementação multifacetada dependente de cada contexto. Por isso, consideraram que as reformas baseadas em políticas de accountability não só empregam diferentes lógicas, como seguem formas mistas em sua implementação. Por terem identificado variações internas nos países da amostra, os pesquisadores sugeriram que tal fenômeno era justificado pelas diferenças existentes nas políticas de uma mesma região e que mais atenção deveria ser dada às lógicas subjacentes da accountability em diferentes níveis (escolas, regiões).

Muito embora marcada por variâncias em seus modelos, as políticas de accountability reforçam o uso cada vez mais frequente de dados quantitativos que põem em centralidade as avaliações em larga escala como elemento da governança educacional, associados à responsabilização de agentes. Por isso, Verger, Fontdevila e Parcerisa (2019) propõem a problematização dos instrumentos de políticas aventados pelas reformas educacionais na medida em que estes contribuem para aplicação de mudanças substantivas na governança das políticas públicas.

No Brasil, o levantamento da literatura revelou que não há consenso da comunidade acadêmica quanto ao tema, sobretudo quando considerados os efeitos de iniciativas como essas. Para Freitas (2011), a accountability pode ser compreendida pela imposição de consequências sérias - entendidas como castigo - sobre alunos, educadores e escolas com base em pontuações que desconsideram fatores contextuais. Essa concepção diverge daquela discutida por Brooke (2013a) sobre as finalidades práticas dessa iniciativa, que seria de expressar uma abordagem em que as escolas, por meio de incentivos financeiros, mudariam suas práticas, esforçando-se para atingir metas e, assim, contribuindo para a aprendizagem do alunado.

A accountability educacional se coloca como um elemento da nova regulação dos sistemas educacionais, construída com base nas avaliações em larga escala, muitas das quais coordenadas pelos governos centrais, que tendem a responsabilizar e publicizar a atuação de diferentes atores dos sistemas educativos, seja de forma explicita, seja de forma implícita. No próximo tópico, são apresentadas as especificidades do sistema de accountability de uma unidade federativa do Brasil. 


\section{O Ceará e o sistema de accountability educacional}

No Ceará, o lado mais específico de processos de accountability, os sistemas de avaliação, remonta a 1992, quando da criação do Sistema Permanente de Avaliação da Educação Básica do Ceará (Spaece). Essa iniciativa, pioneira entre os estados da federação, teve como objetivos principais o fomento de uma cultura de avaliação e a institucionalização de uma política de acompanhamento dos resultados escolares, contribuindo, assim, para a formulação e o aperfeiçoamento das políticas educacionais.

Dessa maneira, o Ceará já despontava como unidade da federação que sistematizava uma experiência de avaliação em rede, uma atividade que lançou bases para a criação, mais tarde, de uma forte política de avaliação, de prestação de contas e de responsabilização. A partir de 2007, o Spaece assumiu o protagonismo no desenho de uma política educacional cujo monitoramento é feito pelos resultados alcançados pelos alunos. Aplicado de forma censitária nas redes estadual e municipais, o Spaece passou a ser o vórtice sobre o qual se aglutina parcela expressiva das iniciativas de políticas para a rede estadual e orienta a pauta do pacto federativo com os municípios no chamado regime de colaboração.

No processo de institucionalização da accountability nesta unidade da federação, um elemento sempre presente foi a colaboração intergovernamental. A colaboração entre entes da federação é um princípio constitucional que pretende sanar as desigualdades entre os locais, buscando reduzir seus efeitos. Na educação, esse princípio é de fundamental importância já que ela é responsabilidade compartilhada entre os entes da federação. No Ceará, a oferta dos anos iniciais e finais do ensino fundamental são, em sua quase totalidade, responsabilidade dos municípios, chegando, em 2018, a 99,4\% e $94,4 \%$, respectivamente. Assim, na estruturação do regime de colaboração, foi suprimida a disputa por matrículas, fazendo com que a colaboração se estabelecesse no âmbito da concepção de políticas de gestão das redes de ensino.

Ocorre que tanto as formas de colaboração entre estado e municípios como o modelo de gestão por resultados adotado no âmbito da governança estadual são tributárias de condições históricas da política educacional que propiciaram a ambiência para implementação de mecanismos de responsabilização, numa clara mudança de paradigma da gestão pública e das relações intergovernamentais.

Essas condições históricas são apresentadas por Vieira e Vidal (2013), quando tratam do regime de colaboração num quadro de três períodos, em que a sua consolidação ocorre a partir do ano de 2007, com o 
Programa Alfabetização na Idade Certa. Por sua vez, Albuquerque e Ramos (2015) apresentam um quadro histórico de três dimensões para discutir a política da gestão por resultados no Ceará, sendo 2007 também, marco de sua efetivação. Esses quadros, quando vistos em complementação, concorrem para a afirmação de Ruff (2019) de que as condições históricas e culturais dos estados implicam a concepção e a implementação das políticas de responsabilização e a maneira como impõem sua autonomia frente às iniciativas do governo central.

Criado pela Lei estadual $n^{\circ} 14.026 / 2007$, o Programa Alfabetização na Idade Certa (PAIC) torna-se política pública para prestar cooperação técnica e financeira aos municípios cearenses com vistas à melhoria dos resultados de aprendizagem. Inicialmente essa política atendia aos anos iniciais do ensino fundamental (até o $2^{\circ}$ ano). Em seguida, o programa passou por dois momentos de expansão, em 2011, quando passa a atender até $05^{\circ}$ ano (intitulando-se PAIC +5) e, em 2016, quando é estendido ao $9^{\circ}$ ano do ensino fundamental II (MAISPAIC).

O PAIC é articulado, em regime de colaboração, pela Secretaria Estadual de Educação, pelas Coordenadorias Regionais de Desenvolvimento da Educação (Crede) e pelas gerências municipais dos 184 municípios signatários do programa. Desde o início, foi estruturado em torno de 5 eixos que compreendem, por um lado, a relação ensino-aprendizagem e, por outro, o gerenciamento das redes de ensino municipais, sendo eles I - Educação Infantil; II - Gestão Pedagógica - Alfabetização e Formação de Professores; III - Gestão da Educação Municipal; IV - Formação do Leitor; V - Avaliação Externa de Aprendizagem (Ceará, 2012). O programa recomenda a difusão de uma cultura de gestão eficaz por meio do eixo da Gestão da Educação Municipal e o eixo da Avaliação Externa, que incide, sobretudo, na concepção da avaliação como um instrumento de intervenção pedagógica.

0 modelo de accountability educacional no Ceará teve início no ano de 2007, quando da criação do Programa Alfabetização na Idade Certa (PAIC), mais tarde associado a outros dois mecanismos de indução financeira: o Prêmio Escola Nota 10 (PEN10) e o rateio da cota-parte do Imposto sobre Circulação de Mercadorias e Serviços (ICMS). Ambos têm como base os índices do Sistema Permanente de Avaliação da Educação Básica do Ceará (Spaece), sob o qual são avaliados todos os 184 municípios do estado, corroborando para a construção de um modelo de coordenação federativa e regulação na educação.

A implementação do PAIC no Ceará contou também com as orientações do Banco Mundial (BM), que associou as metas de um empréstimo multisetorial realizado no ano de 2009 - Operação SWAp II - às especifici- 
dades do programa de alfabetização. Essa relação, permite compreender o modo de atuação do BM, revelando, de maneira bastante objetiva, os aspectos pragmáticos e técnicos dessa ação.

O Banco Mundial é uma peça importante no jogo da política educacional ao atuar como investidor internacional. Longe de tratar apenas de financiamentos de recursos para projetos, as ações empreendidas por esse organismo internacional influenciam fortemente a concepção política adotada no setor educacional dos países em desenvolvimento, bem como no modelo de avaliação dessas políticas. Em outras palavras, o recebimento de recursos significa a aplicação das orientações desejadas pelo emprestador. Como advogam Verger e Parcerisa (2017), para o Banco Mundial as políticas de accountability são peças-chave na reforma educacional, por isso ele se utiliza de informes e de operações de empréstimos para divulgá-las.

No Ceará, a adoção da concepção de governo empresarial e de modelos de accountability surgem como condição de desembolso do empréstimo na modalidade Sector Wide Approach ${ }^{1}$ (SWAp), contratado, no ano de 2009, pelo estado do Ceará junto ao Banco Mundial. O projeto, iniciado em 2009, deu seguimento à operação iniciada no ano de 2005. Nas duas fases da operação, exigiu-se uma visão multisetorial para alcance de indicadores ${ }^{2}$.

No setor da educação, as metas foram definidas em torno do eixo de avaliação e da cooperação intergovernamental, porquanto tratam de avaliar a aprendizagem dos estudantes do $2^{\circ}, 5^{\circ}$ e $9^{\circ}$ anos do ensino fundamental $^{3}$ e de apoiar os gerentes do PAIC nos municípios. Essas ações se coadunam com os três programas elegíveis para o financiamento do setor, além de estarem alinhadas aos objetivos específicos do PAIC nos eixos de gestão municipal da educação e da avaliação externa, presentes também nos indicadores secundários que foram definidos: "Avaliação da implementação municipal do programa 'Alfabetização da Idade Certa' [sic] (uma em 2009 e uma em 2011); [e] Obtenção da alfabetização na $2^{a}$ série”. Como informa a Deliberação n. 55/2010 desse órgão, os indicadores sobre o analfabetismo escolar e a avaliação do desempenho da aprendizagem estiveram na pauta de deliberação para a Seduc nos primeiros anos de operacionalização da SWAp II (Ceará, 2010).

${ }^{1}$ Do inglês, Abordagem Setorial Abrangente.

2 "O empréstimo modalidade SWAp (Sector Wide Approach) do Estado do Ceará com o Banco Mundial tem como base o SWAp I, no valor de US \$150 milhões iniciado em 2005 que deu suporte à agenda de desenvolvimento social do Estado e que foi concluído em 2007. O contrato do SWAp II, no valor de US \$ 240 milhões, foi assinado em 2009 e concluído em 2012". Disponível em: https://www.ipece.ce.gov.br/projeto-swap-i-e-ii/.

${ }^{3}$ Além das séries do ensino fundamental, entre as metas de desembolso está a avaliação do $3^{\circ}$ ano do ensino médio, identificado como $12^{\circ}$ ano do percurso escolar. 
Tanto os interesses do BM como os da Secretaria Estadual de Educação do Ceará estavam entrelaçados, uma vez que a Seduc apresentou, como metas, ações de um programa que já haviam sido iniciadas em 2007, e o BM as ratificou, pois estavam em acordo com o seu projeto de educação. Ao mesmo tempo, os interesses comuns facilitam o marketing das ações, fazendo do Ceará um case de sucesso a ser replicado.

A leitura do Quadro 1 permite observar que, desde o ano de 2007, quando um novo grupo político assumiu a direção do estado, as regras e as normas criadas tiveram por finalidade fortalecer a organização do Programa Alfabetização na Idade Certa ou servir como políticas de indução para os municípios, uma vez que afirma a centralidade dos eixos de gestão municipal e avaliação da aprendizagem já elencados no programa, mas associados ao rateio da cota-parte do ICMS e ao Prêmio Escola Nota Dez.

Quadro 1. Histórico da legislação da accountability no Ceará

\begin{tabular}{|c|c|c|}
\hline Instrumento & Data & Conteúdo \\
\hline Lei 13.875 & $\begin{array}{l}7 \text { de fevereiro de } \\
2007\end{array}$ & $\begin{array}{l}\text { Apresenta a gestão por resultados como modelo } \\
\text { administrativo do governo estadual }\end{array}$ \\
\hline $\begin{array}{l}\text { Protocolo de intenções } \\
\text { firmado entre o Governo } \\
\text { Estadual e os municípios }\end{array}$ & $\begin{array}{l}24 \text { de maio de } \\
2007\end{array}$ & $\begin{array}{l}\text { Estado e municípios firmam compromisso para } \\
\text { execução do Programa Alfabetização na Idade } \\
\text { Certa, com contrapartida de cada um. }\end{array}$ \\
\hline Lei Complementar $n^{\circ} 63$ & $\begin{array}{l}4 \text { de setembro de } \\
2007\end{array}$ & $\begin{array}{l}\text { Altera a regra que impossibilitava concessão de } \\
\text { bolsa para servidores públicos, com recursos } \\
\text { do FECOP, por período superior a três anos; }\end{array}$ \\
\hline Lei $n^{\circ} 14.023$ & $\begin{array}{l}17 \text { de dezembro } \\
\text { de } 2007\end{array}$ & $\begin{array}{l}\text { Altera os critérios para distribuição da parcela } \\
\text { do ICMS, associando } 18 \% \text { aos resultados do } \\
2^{\circ} \text { ano do ensino fundamental }\end{array}$ \\
\hline Lei $n^{\circ} 14.026$ & $\begin{array}{l}17 \text { de dezembro } \\
\text { de } 2007\end{array}$ & $\begin{array}{l}\text { Cria o Programa Alfabetização na Idade Certa } \\
\text { para prestar cooperação técnica e pedagógica } \\
\text { aos municípios }\end{array}$ \\
\hline Decreto n²9.139 & $\begin{array}{l}26 \text { de dezembro } \\
\text { de } 2007\end{array}$ & $\begin{array}{l}\text { Altera a estrutura organizacional da Secretaria } \\
\text { Estadual de Educação, criando a Coordenadoria } \\
\text { de Cooperação com os Municípios e os Núcleos } \\
\text { Regionais de Cooperação com os Municípios }\end{array}$ \\
\hline $\begin{array}{l}\text { Contrato de Financia- } \\
\text { mento da Operação Swap } \\
\text { II junto ao Banco Mun- } \\
\text { dial- Diário Oficial do } \\
\text { Estado do Ceará }\end{array}$ & $\begin{array}{l}24 \text { de abril de } \\
2009\end{array}$ & $\begin{array}{l}\text { Financiamento do projeto de Apoio à Inclusão } \\
\text { Social e ao Desenvolvimento Econômico do } \\
\text { Ceará - SWAp II, com ações especificas para a } \\
\text { Secretaria Estadual de Educação com foco no } \\
\text { Programa Alfabetização na Idade Certa }\end{array}$ \\
\hline Lei $n^{\circ} 14.371$ & $\begin{array}{l}19 \text { de junho de } \\
2009\end{array}$ & $\begin{array}{l}\text { Cria o Prêmio Escola Nota Dez para turmas do } \\
2^{\circ} \text { ano do ensino fundamental }\end{array}$ \\
\hline $\begin{array}{l}\text { Termo de Parceria de Re- } \\
\text { sultados firmado entre o } \\
\text { Governo Estadual e enti- } \\
\text { dades da sociedade civil }\end{array}$ & $\begin{array}{l}25 \text { de maio de } \\
2011\end{array}$ & $\begin{array}{l}\text { Manutenção, aperfeiçoamento e ampliação do } \\
\text { Programa Alfabetização na Idade Certa }\end{array}$ \\
\hline
\end{tabular}




\begin{tabular}{cll}
\hline Instrumento & \multicolumn{1}{c}{ Data } & \multicolumn{1}{c}{ Conteúdo } \\
\hline Decreto $n^{\circ} 30.796$ & $\begin{array}{l}29 \text { de dezembro } \\
\text { de } 2011\end{array}$ & $\begin{array}{l}\text { Altera os critérios para distribuição da parcela } \\
\text { do ICMS, associando } 18 \% \text { aos resultados do } \\
2^{\circ} \text { e } 5^{\circ} \text { ano do ensino fundamental }\end{array}$ \\
\hline Decreto $n^{\circ} 30.797$ & $\begin{array}{l}29 \text { de dezembro } \\
\text { de } 2011\end{array}$ & $\begin{array}{l}\text { Amplia o Prêmio Escola Nota Dez para turmas } \\
\text { do } 5^{\circ} \text { ano do ensino fundamental }\end{array}$ \\
\hline Lei $n^{\circ} 15.922$ & $\begin{array}{l}15 \text { de dezembro } \\
\text { de } 2015\end{array}$ & $\begin{array}{l}\text { Altera os critérios para distribuição da parcela } \\
\text { do ICMS, associando } 18 \% \text { aos resultados do } \\
2^{\circ}, 5^{\circ} \text { e } 9^{\circ} \text { ano do ensino fundamental }\end{array}$ \\
\hline Lei $n^{\circ} 15.923$ & $\begin{array}{l}15 \text { de dezembro } \\
\text { de } 2015\end{array}$ & $\begin{array}{l}\text { Amplia o Prêmio Escola Nota Dez para turmas } \\
\text { do } 9^{\circ} \text { ano do ensino fundamental, retirando a } \\
\text { possibilidade de apoio as turmas do } 2^{\circ} \text { ano }\end{array}$ \\
\hline Lei $n^{\circ} 17.130$ & $\begin{array}{l}12 \text { de dezembro } \\
\text { de } 2019\end{array}$ & $\begin{array}{l}\text { Altera os critérios para distribuição da parcela } \\
\text { do ICMS }\end{array}$ \\
\hline
\end{tabular}

Fonte: Elaboração própria.

De fato, o interesse do governo estadual na proposição dessas regras era o de privilegiar "[...] um modelo de gestão pública por resultados e [induzir] os municípios a agir pela melhoria dos indicadores sociais" (Ceará, 2012, p. 86). Embora a gestão por resultados, regulamentada pela Lei $n^{\circ}$ 13.875/2007, tenha sido adotada como modelo administrativo do estado desde 0 ano de 2004, a pretensão de que os municípios também aderissem à iniciativa similar é reflexo de como o governo estadual queria expandir esse tipo de gestão, para o que foi preciso criar as políticas de indução supracitadas com o discurso de que era preciso "fortalecer, valorizar e ampliar" os trabalhos de municípios e escolas.

Esse aspecto é importante de ser observado pois confirma que, diferentemente de outros entes da federação, nesta unidade subnacional não houve o esvaziamento do papel estadual na coordenação de uma política educacional no território sobre o qual tem jurisdição, aspecto também notado por Vieira, Plank e Vidal (2019, p. 5) quando concordam que "[... ] o governo estadual [...] exerceu protagonismo central na formulação e implementação de políticas, estimulando a participação de outros agentes e atores".

Por outro lado, essa condição confirma a criação de elementos para a regulação institucional, ao revelar um conjunto de mecanismos que tendem a orientar, coordenar e controlar as ações dos estabelecimentos e dos profissionais no âmbito do sistema educativo, tal qual definiu Maroy (2011). Dessa forma, a captura dos instrumentos mobilizados pelo estado do Ceará em torno da política educacional revela seu controle político sobre as municipalidades, como também a implementação de um sistema de accountability que introduz regras e constrangimentos. De maneira direta, esse conjunto de normas institucionaliza a colaboração entre os entes gover- 
namentais, a regulação e os componentes da accountability. A concepção de institucionalização tratada por Lascoumes e Le Galès (2012, p. 190) ajuda a compreender que as normativas criadas no Ceará privilegiam interesses na condução da política estadual, uma vez que, para estes autores,

o processo de institucionalização repousa sobre as dinâmicas para as quais as regras e os procedimentos aparecem, se desenvolvem ao ponto de constituir um espaço social e produzem em definitivo comportamentos dos atores que os gerou ou os integrou. De maneira mais precisa, o processo de institucionalização pode ser observado logo que as regras e os procedimentos sejam cada vez mais números, ganham em precisão e tornam-se realmente prescritivos.

Na Figura 1, são ilustrados os principais elementos mobilizados no sistema de responsabilização do Ceará.

Figura 1. Elementos do sistema de accountability no Ceará

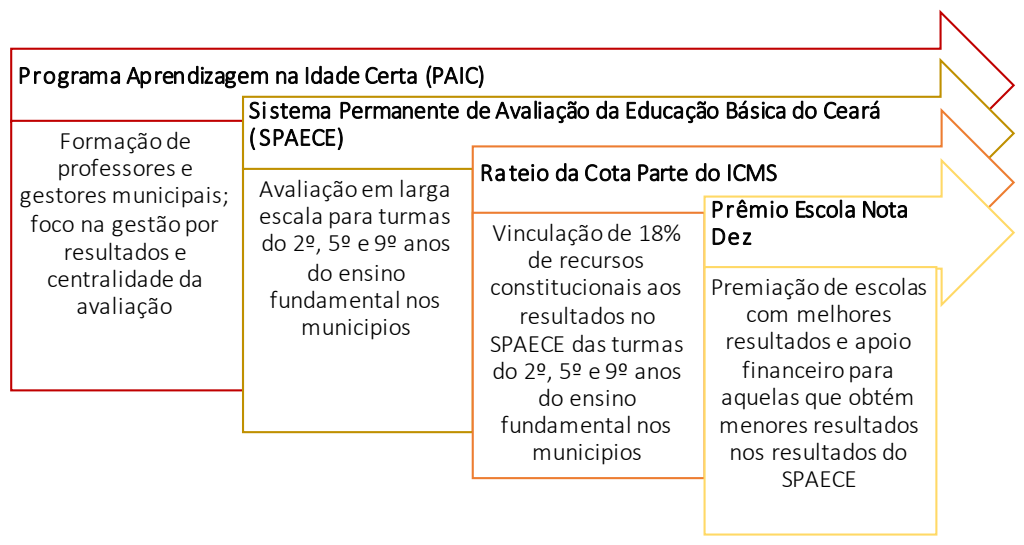

Fonte: Elaboração própria.

Nos tópicos a seguir, são apresentadas as especificidades de duas dessas políticas: o rateio da cota-parte do ICMS e o Prêmio Escola Nota 10.

\subsection{Mudanças na regra do rateio do Imposto sobre Operações relativas}

à Circulação de Mercadorias e Prestação de Serviços (ICMS)

O grupo político que assume o governo estadual em 2007 trouxe algumas mudanças na agenda das políticas educacionais, entretanto, sem representar ruptura com iniciativas de governos anteriores. À afirmação da gestão por resultados como modelo de gestão do poder executivo, pela Lei ${ }^{0}$ 
13.875/07, somou-se à implantação do PAIC (Lei no 14.026/07) e a restruturação do organograma da Secretaria Estadual de Educação (Seduc), criando a Coordenadoria de Cooperação com os Municípios, pela Lei n 14.048/07.

Nesse ordenamento legal, o fortalecimento do regime de colaboração passou a figurar entre os principais objetivos do governo estadual, continuado nos últimos doze anos. Entre essas novas regras, a vinculação da distribuição da cota-parte do ICMS a indicadores educacionais tratou de afirmar o papel estratégico do setor em relação às políticas do estado e garantir o comprometimento de gestores municipais. O ICMS é um imposto cobrado pelo Estado que corresponde a circulação de bens e serviços no território. A distribuição do ICMS aos municípios é um preceito presente no artigo 158 da Constituição Federal de 1988, sendo que do total arrecadado pelo estado, três quartos, no mínimo, retornarão de forma proporcional às operações realizadas no município, e, até um quarto, "de acordo com o que dispuser lei estadual". Esse último repasse é conhecido como cota-parte.

A legislação estadual, pela Lei $n^{\circ} 12.612 / 96$, dispunha que a parcela de $25 \%$ oriunda de receita do ICMS teria $12,5 \%$, vinculados ao somatório das despesas realizadas pelo município na manutenção e desenvolvimento do ensino. Esse mecanismo foi alterado pela Lei $n^{\circ} 14.023 / 07^{4}$, que vinculou o percentual da cota-parte do ICMS a dois novos critérios:

II - 18\% (dezoito por cento) em função do Índice Municipal de Qualidade Educacional [IQE] de cada município, formado pela taxa de aprovação dos alunos do $1^{\circ}$ ao $5^{\circ}$ ano do ensino fundamental e pela média obtida pelos alunos de $2^{\circ}$ e $5^{\circ}$ ano da rede municipal em avaliações de aprendizagem.

Em tese, as alterações na divisão da cota-parte do ICMS entre os municípios cearenses acompanham as mudanças na concepção de qualidade da educação. Se antes, o quanto 'gasta' e 'quantos alunos' dizia muito sobre as redes de ensino, com a centralidade das avaliações externas, os indicadores dos testes passaram a nortear a definição de qualidade. Avaliação de desempenho e qualidade da educação, tratadas como sinônimos, passaram a habitar o imaginário social e a orientar as políticas municipais de educação.

Considerando que a cota-parte do ICMS a ser rateado entre os municípios passa a ter $72 \%$ de seu valor indexado a resultados educacionais, calculados pela taxa de aprovação e pela proficiência em avaliação de larga escala, o estado estimula uma 'corrida' de obstáculos entre redes municipais distintas em tamanho, problemas e características. Coloca sob os mesmos

${ }^{4}$ Além dos $18 \%$ vinculados aos índices educacionais, $5 \%$ foram vinculados aos resultados na área da saúde (IQS) e $2 \%$ em função dos resultados do meio ambiente (IQM). 
critérios redes que variam de 2 a 190 escolas, com matrículas que variam de 100 a 100.000 alunos, escolas com infraestruturas muito diversas etc. Como não há dinheiro novo, os municípios que avançam nos seus resultados e aumentam o IQE, são premiados com recursos que provem daqueles que não conseguiram alcançar melhorias de modo a aumentar o IQE. Desde a criação da lei, a capital do estado, Fortaleza, é quem tem perdido mais recursos, em beneficio, especialmente, dos municípios de pequeno porte, com redes escolares pequenas, nas quais a focalização de iniciativas em torno da melhoria das taxas de aprovação e de aumento da proficiência dos alunos surte efeitos mais rapidamente do que em redes constituídas de muitas escolas e com alta complexidade de gestão do sistema.

Se, por um lado, as mudanças na legislação do ICMS criam uma ambiência favorável a responsabilização educacional, por outro lado, ao estabelecer os mesmos critérios para todos os municípios, independente da complexidade e tamanho das redes escolares, cria uma 'competição desigual' entre os municípios, o que acaba criando situações de iniquidade entre eles.

\subsection{O Prêmio Escola Nota Dez: escola premiada x escola apoiada e a punição invisível}

O Prêmio Escola Nota 10 (PEN10) foi criado com o intuito de servir como uma política de indução para que os municípios priorizassem a alfabetização dos alunos do $2^{\circ}$ ano do ensino fundamental. Coordenado pelo governo estadual, foi instituído em junho de 2009, pela Lei $n^{\circ} 14.371$, destinado a premiar as escolas públicas com os melhores resultados no Índice de Desempenho Escolar - Alfabetização (IDE-Alfa). Nesse sentido, e baseado no que se tem discutido na literatura, é considerado uma política de accountability forte, pois assegura premiação em dinheiro para escolas, e, consequentemente, para professores e profissionais da educação.

Desde sua aprovação, o PEN10 já passou por mudanças em sua concepção, principalmente no que diz respeito às series premiadas. Em 2009 , ele se destinava às escolas que possuíam turmas do $2^{\circ}$ ano do ensino fundamental que tivessem pelo menos 20 alunos matriculados, sendo as 150 maiores notas (entre 8,5 e 10) do IDE-Alfa - escolas premiadas e as 150 menores notas, as escolas apoiadas. A premiação era calculada pelo número de alunos do $2^{\circ}$ ano avaliado pelo Spaece-Alfa sendo multiplicado por $\mathrm{R} \$ 2.500,00$ para as escolas premiadas e $\mathrm{R} \$ 1.250,00$ para as apoiadas. Essas condições, por si, revelam a diferenciação existente entre as escolas apoiadas e as premiadas, uma vez que o valor atribuído ao aluno penaliza justamente aqueles que já enfrentam dificuldades educacionais. 0 valor do prêmio associado ao aluno dos dois tipos de escola já traz, em seu escopo 
original, uma desigualdade na origem, expressa por meio de uma "punição invisível", simbolicamente associada a um "prêmio" e revela, assim, que a meritocracia como critério pode acentuar desigualdades, quando o objetivo seria aumentar a equidade.

Autores como Brooke (2013b) e Calderón, Raquel e Cabral (2015) destacam a forma de financiamento do Prêmio como um elemento inovador nas políticas educacionais do país, o que, de certa maneira, atenuaria o caráter forte de responsabilização no programa, isso porque as escolas premiadas seriam responsáveis por tutorar uma das escolas apoiadas. Brooke (2013b, p. 132), por exemplo, trata de justificar a diferenciação existente entre premiações individuais e premiações coletivas a partir do PEN10. Para esse autor, as experiências existentes de bonificação a partir de avaliações de desempenho são pagas coletivamente "[...] com justificativas que geralmente explicitam o propósito de motivar toda a equipe e evitar possíveis divisões pelos incentivos individuais".

Em 2011, ocorrem novas alterações, e o PEN10 passa a premiar e apoiar, além de escolas do $2^{\circ}$ ano, escolas do $5^{\circ}$ ano do ensino fundamental, especificamente as que obtivessem o IDE-5 entre 7,5 e 10. Diferente da primeira legislação, as alterações de 2011 também incluíram, como condição para a premiação, o Fator de Ajuste Universalizado do Aprendizado, criado para "[...] estimular as escolas a incluírem um maior percentual de alunos nos níveis adequados" (Ceará, 2011), com vistas à equalização dos resultados na escola e nas redes. Portanto, as condições que qualificam uma escola premiada seria a ponderação (i) da proficiência da escola numa escala de 0 a 10; (ii) o Fator de Ajuste Universalizado e (iii) a taxa de participação na avaliação. As mudanças também trataram de diminuir o valor per capita por aluno avaliado - $\mathrm{R} \$ 2.000,00$ para a escola premiada e $\mathrm{R} \$ 1.000,00$ para a escola apoiada.

Além dos valores estabelecidos por aluno, outra diferença financeira se faz presente. Trata-se da forma de liberação das duas parcelas: enquanto as escolas premiadas recebem $75 \%$ do prêmio na primeira parcela, as apoiadas recebem $50 \%$. A segunda parcela é condicionada a critérios que, em grande medida, não são atingidos pelas escolas. Mais uma vez, essa diferença no percentual de liberação do prêmio, penaliza, em maior intensidade, as escolas apoiadas, intensificando uma "punição invisível".

Outra especificidade na gestão do prêmio diz respeito à forma como as escolas podem aplicar os recursos liberados. A escola premiada e a apoiada devem elaborar um plano de aplicação que vise "à melhoria das suas condições e dos resultados de aprendizagem de seus alunos". O Quadro 2 mostra as regras para aplicação dos recursos. 
Quadro 2. Regras de aplicação no Prêmio Escola Nota 10

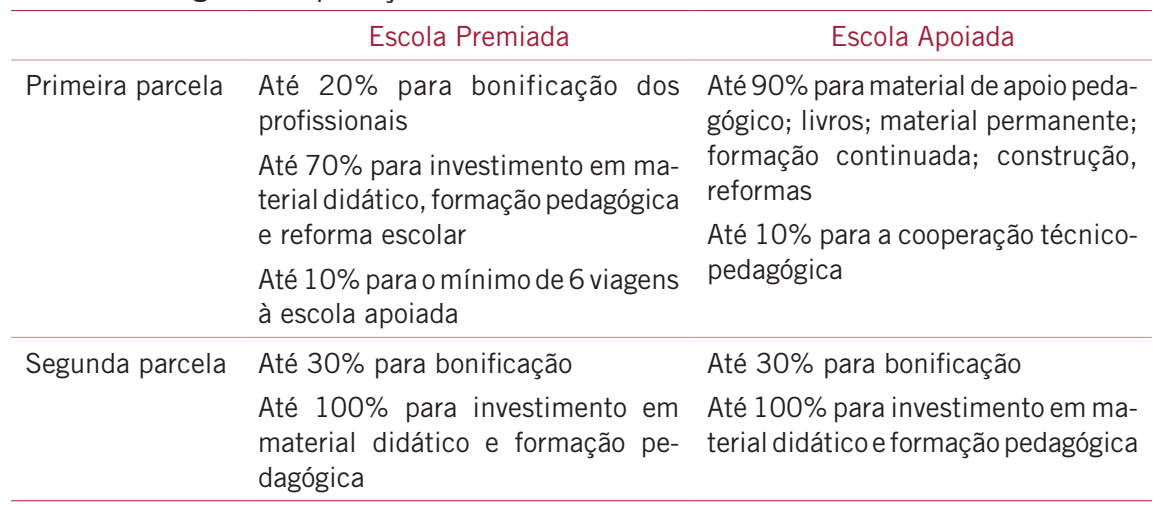

Fonte: Elaboração própria.

As regras de aplicação dos recursos para as escolas têm, na bonificação dos profissionais da educação, a maior diferença. Enquanto as escolas premiadas podem aplicar até $22,5 \%$ dos recursos recebidos na bonificação dos professores das séries premiadas, do núcleo gestor e demais profissionais lotados no ano de referência da premiação, as escolas apoiadas só podem fazer no recebimento da segunda parcela no valor de até $15 \%$ do prêmio.

O PEN10 é administrado pela Secretaria Estadual de Educação e financiado pelo Fundo Estadual de Combate à Pobreza (FECOP), que tem assumido papel de destaque do arranjo da accountability educacional no Ceará. Tendo atingido o valor máximo de $\mathrm{R} \$ 30$ milhões previstos para os anos de 2010, 2011 e 2012, os recursos para o PEN10 começam a ter seu orçamento reduzido, chegando em 2016 a representar $56,2 \%$ dos anos áureos.

0 Quadro 3 mostra, a partir dos dados obtidos na Seduc (2019), os valores pagos no período 2010 - 2016 às escolas premiadas e apoiadas.

Quadro 3. Valores pagos no período 2010 - 2016, escolas apoiadas e premiadas

\begin{tabular}{cccc}
\hline Ano & Valor Pago Escolas Apoiadas Valor Pago Escolas Premiadas & Valor Pago Total \\
\hline 2010 & $9.511 .875,00$ & $13.265 .625,00$ & $22.777 .500,00$ \\
\hline 2011 & $10.258 .000,00$ & $18.321 .375,00$ & $28.579 .375,00$ \\
\hline 2012 & $4.697 .000,00$ & $11.103 .000,00$ & $15.800 .000,00$ \\
\hline 2013 & $6.638 .300,00$ & $15.770 .750,00$ & $22.409 .050,00$ \\
\hline 2014 & $8.017 .500,00$ & $14.488 .688,00$ & $22.506 .188,00$ \\
\hline 2015 & $4.827 .500,00$ & $17.962 .500,00$ & $22.790 .000,00$ \\
\hline 2016 & $4.607 .500,00$ & $14.957 .000,00$ & $19.564 .500,00$ \\
\hline Total & $48.557 .675,00$ & $105.868 .938,00$ & $154.426 .613,00$ \\
\hline
\end{tabular}

Fonte: Secretaria da Educação do Ceará, 2019. 
0 quadro mostra que do total liberado, apenas $31,4 \%$ foi destinado as escolas apoiadas. Esses dados alertam para uma necessária avaliação sobre a concepção do PEN10, à medida em que se observa sinais de desequilíbrio numa iniciativa de política pública que pretendia ampliar as oportunidades educacionais dos mais vulneráveis. Nesse sentido, o PEN10 revela uma accountability baseada na meritocracia, deixando, em segundo plano, a criação de mecanismos que visem a favorecer a justiça escolar.

Marcado por práticas conduzidas a resultados, com um viés meritocrático a orientar seus critérios, o prêmio traz, em seu escopo, questões problemáticas que emergiram na sua implementação, como os desequilíbrios no pagamento das parcelas e dos valores destinados. Visto isso, concordando com o estudo de Yan (2019) sobre como os governos têm praticado a accountability, é possível afirmar que o desenho da proposta leva a diferenças substanciais, partindo da conceituação de escola premiada e apoiada.

\section{Considerações finais}

Neste artigo, buscou-se compreender a política de accountability educacional no Ceará a partir das mudanças da governança do estado na coordenação estadual. Esse exercício foi possível, quando, observando a política, verificou-se que os instrumentos mobilizados procuram alterar 0 comportamento tanto da gestão no nível da escola como no nível do sistema educacional, afirmando um sistema de accountability a partir de normatizações que não podem ser encaradas apenas como regulamentações, mas por regulação.

Nessa unidade subnacional, não apenas foi instituído um sistema de accountability comportado pela avaliação, pela responsabilização e pela prestação de contas (muito embora caracterizados por um modelo gerencial), mas também cada um desses pilares foi sendo associado a arranjos políticos e financeiros tão complexos quanto a constituição dos primeiros e que, coordenado pelo governo estadual, facilitou a criação de mecanismos de indução à luz, inclusive, das regras constitucionais.

Por isso, por se tratar de uma situação que envolve a questão federativa, visto que aborda a relação intergovernamental entre o governo estadual e os municípios de sua abrangência, a análise revelou que a cooperação e a coordenação entre os entes federativos podem ser compreendidas como parte de uma nova regulação da ação pública direcionadas por um sistema de accountability educacional. 


\section{Agradecimentos}

À Coordenação de Aperfeiçoamento de Pessoal de Nível Superior (CAPES, Brasil) pela concessão de bolsa de pesquisa - Código de Financiamento 001.

\section{Referências}

Afonso, A. J. (2010). Um olhar sociológico em torno da accountability em educação. En M. T Esteban e A. J. Afonso, (Coord.), Olhares e interfaces: reflexões sobre a avaliação (147-170). São Paulo: Cortez.

Afonso, A. J. (2009). Avaliação educacional: regulação e emancipação. São Paulo: Cortez.

Afonso, A. (2018). Políticas de responsabilização: equívocos semânticos ou ambiguidades político-ideológicas?. Revista de Educação PUC-Campinas, 23(1), 8-18. https:// doi.org/10.24220/2318-0870v23n1a4052.

Aguilar, L. F. (2010). Gobernanza: El nuevo proceso de gobernar. Ciudad de México: Fundación Friedrich Naumann.

Albuquerque, F. C. A., e Ramos, J. F. P. (2015). Gestão Educacional no Ceará: da autonomia escolar à política de resultados (1995-2010). En E. M. N. Diógenes e F. A. Andrade, (Coord.), Temas de educação: olhares e caminhos (125-135). Curitiba: CRV.

Anderson, G. (2017). Privatizing subjectivities: how New Public Management (NPM) is designing a "new" professional in education. RBPAE, 33(3), 561 - 592. https://doi.org/10.21573/ vol33n32017.79296.

Anderson, J. A. (2005). Accountability in education. Paris: International Institute for Educational Planning; Brussels: International Academy of Education.

Bauer, A., Pimenta, C. O., Neto, J. L. H., \& Sousa, S. Z. L. (2015). Avaliação em larga escala em municípios brasileiros: o que dizem os números? Estudos em Avaliação Educacional, 26(62), 326-352. http://dx.doi.org/10.18222/eae266203207.

Barroso, J. (2005). O Estado, a educação e a regulação das políticas públicas. Educação \& Sociedade, 26(92), 725-751. https://doi.org/10.1590/S0101-73302005000300002.

Barroso, J. (2006). O Estado e a educação: a regulação internacional, a regulação nacional e a regulação local. En J. Barroso (Coord.), A regulação das políticas públicas de educação: espaços, dinâmicas e actores (41-70). Lisboa: EDUCA e Unidade de I\&D em Ciências da Educação.

Brooke, N. (2013a). Sobre a equidade e outros impactos dos incentivos monetários para professores. Estudos em Avaliação Educacional, 24(55), 34-62. http://dx.doi. org/10.18222/eae245520132719.

Brooke, N. (2013b). Políticas Estaduais de Responsabilização: Buscando o Diálogo. Em A. Bauer e B. A. Gatti (Coord.), Vinte e cinco ano de avaliação de sistemas educacionais no Brasil: implicações nas redes de ensino, no currículo e na formação de professores (119-146). Florianópolis: Insular.

Calderón, A. I., Raquel, B. M. G., e Cabral, E. S. (2015). O Prêmio Escola nota 10: meritocracia e cooperação para a melhoria do desempenho escolar1. Ensaio: Avaliação e Políticas 
Públicas em Educação, 23(87), 517-540. https://doi.org/10.1590/S010440362015000100021.

Ceará (2010). Deliberação COGERF n 55 /2010. Dispõe sobre Relatórios de Produto-Resultado referentes ao cumprimento de indicadores de desembolso dos recursos da Operação SWAP II.

Ceará 2011. Lei no 15.052, de 06 de dezembro de 2011 (Institui o Prêmio Escola Nota Dez).

Ceará (2012). Regime de Colaboração para a garantia do direito à aprendizagem: o Programa Alfabetização na Idade Certa (PAIC) no Ceará. Fortaleza: SEDUC.

Freitas, L. C. de (2011). A qualidade da escola e os profissionais da educação: confiança nas relações ou cultura da auditoria. En C. Cunha, J. V. Sousa e M. A. da Silva, (Coord.), Políticas públicas de educação na América Latina: lições aprendidas e desafios (279-302). Campinas: Autores Associados.

Kim, T., e Yun, J. T. (2019). Logics of accountability: Cross-national patterns in schoollevel controls. education policy analysis archives, 27(119). https://doi.org/10.14507/ epaa.27.4597.

Lascoumes, P., e Le Galès, P. (2012). Sociologia da ação pública. Maceió: EDUFAL.

Lüdke, M., e André, M. E. D. A. (2014). Pesquisa em Educação: abordagens qualitativas. São Paulo: LTC.

Maroy, C. (2011). Em direção a uma regulação pós-burocrática dos sistemas de ensino na Europa. Em D. A. Oliveira, e A. Duarte, (Coord.), Políticas públicas e educação: regulação e conhecimento (19-46.). Belo Horizonte: Fino Traço.

Ruff, R. (2019). State-level autonomy in the era of accountability: A comparative analysis of Virginia and Nebraska education policy through No Child Left Behind. education policy analysis archives, 27, 6. https://doi.org/10.14507/epaa.27.4013.

Schedler, A. (2004). Que es la rendición de cuentas? Cuadernos de Transparencia, 3.

Schneider, M. P. (2017). Tessituras intergovernamentais das políticas de accountability educacional. Revista Educação em Questão, 55(43), 162-186. https://doi. org/10.21680/1981-1802.2017v55n43ID11811.

Verger, A., Fontdevila, C., e Parcerisa, L. (2019). Reforming governance through policy instruments: how and to what extent standards, tests and accountability in education spread worldwide, Discourse: Studies in the Cultural Politics of Education, 40(2), 248-270. https://doi.org/10.1080/01596306.2019.1569882.

Verger, A., e Parcerisa, L. (2017). La globalización de la rendición de cuentas en el ámbito educativo: una revisión de factores y actores de difusión de políticas. RBPAE, 33(3), 663-684. https://doi.org/10.21573/vol33n32017.79301.

Vieira, S. L., e Vidal, E. M. (2013). Construindo uma história de colaboração na educação: a experiência do Ceará. Educação \& Sociedade, 34(125), 1075-1093. https://doi. org/10.1590/S0101-73302013000400004.

Vieira, S. L., Plank, D. N., e Vidal, E. M. (2019). Política Educacional no Ceará: processos estratégicos. Educação \& Realidade, 44(4), e87353. Epub November 11, 2019. https://doi.org/10.1590/2175-623687353.

Yan, Y. (2019). Making accountability work in basic education: reforms, challenges and the role of the government, Policy Design and Practice, 2:1, 90-102, https://doi.org/10.1 080/25741292.2019.1580131. 